\title{
Report on Periconceptional Folic Acid Supplementation for Switzerland
}

\author{
M.-C. Addor, Registre Vaudois des Anomalies Congénitales (EUROCAT)
}

\section{Folic Acid Supplementation Policy}

In the early 1990s, the Public Health Officer for the canton of Vaud, at the request of the University Department of Gynecology and Obstetrics, asked the Federal Office of Public Health to support the idea of a national recommendation concerning folic acid and the prevention of neural tube defects (NTD) $[1,2]$.

The current recommendations (2002) for primary prevention are as follows:

- $0.4 \mathrm{mg}$ folic acid supplementation (with or without other vitamins) should be taken daily from four weeks before conception until twelve weeks after.

- All women of child bearing age without safe contraception should consume a folate rich diet (fresh fruits and vegetables, whole grain products and fortified food, e.g. cereals and breakfast beverages).

- Women who have had a previous pregnancy affected by a neural tube defect are advised to take the following supplements periconceptionally: 4-5 mg folic acid daily, monopreparation (Folvite, Ac. Folicum, Foli-Rivo) polyvitamins $=0.4-1 \mathrm{mg}$ folic acid (vit $\mathrm{A} \leq$ $8000 \mathrm{Ul})$.

\section{Food Fortification Policy}

In 1997, Wiederkehr et al. submitted to the Swiss representative assembly a proposal for the mandatory fortification of flour with folic acid for the prevention of neural tube defects. Since 2000, the Federal Office of Public Health has been studying the folate situation in Switzerland [3] and a working group of the Swiss Nutrition Council has submitted a report for the Federal Government with scientific recommendations, published in 2002 [4]. The current recommendation regarding fortification is that flour should be fortified on a mandatory basis by $3 \mathrm{mg}$ folic acid and 10 micrograms of vitamin B12 per kg of flour in order to obtain a supplementary daily intake of folic acid of 275 micrograms and about 1 microgram of B12 per day. This is the most efficacious, sure and economic way to prevent NTD.

It should be noted that this recommendation is supported by the Swiss Nutrition Council but not yet by the Federal Office of Public Health. The fortification with folic acid of other foods is under re-evaluation. The potential benefits of folic acid in the Swiss population have now been evaluated and this knowledge will influence the official federal policy for folic acid fortification in Switzerland. At the moment the Federal Office of Public Health is considering the next steps to be taken.

\section{Health Education Initiatives}

A working group of the Federal Office of Public Health is preparing a booklet and a leaflet for women in childbearing age. Some booklets, edited by pharmacists "vitamin info" are available in waiting rooms of gynaecologists.

\section{Uptake and Knowledge of Folic Acid}

The percentage of pregnancies that are planned in Switzerland is very low and there are very few "preconceptional consultations". Awareness in the child bearing population of the recommendations regarding folic acid supplementation is still poor. In Switzerland, the daily dietary intake of folate has been estimated to be $275 \mu$ g or even less.

\section{Laws Regarding Termination of Pregnancy}

Termination of pregnancy is legal up to 24 weeks gestation. Thereafter, it is not legal for any indication. 
Figure 1

Switzerland (Vaud): Total Prevalence Rate for Neural Tube Defects.

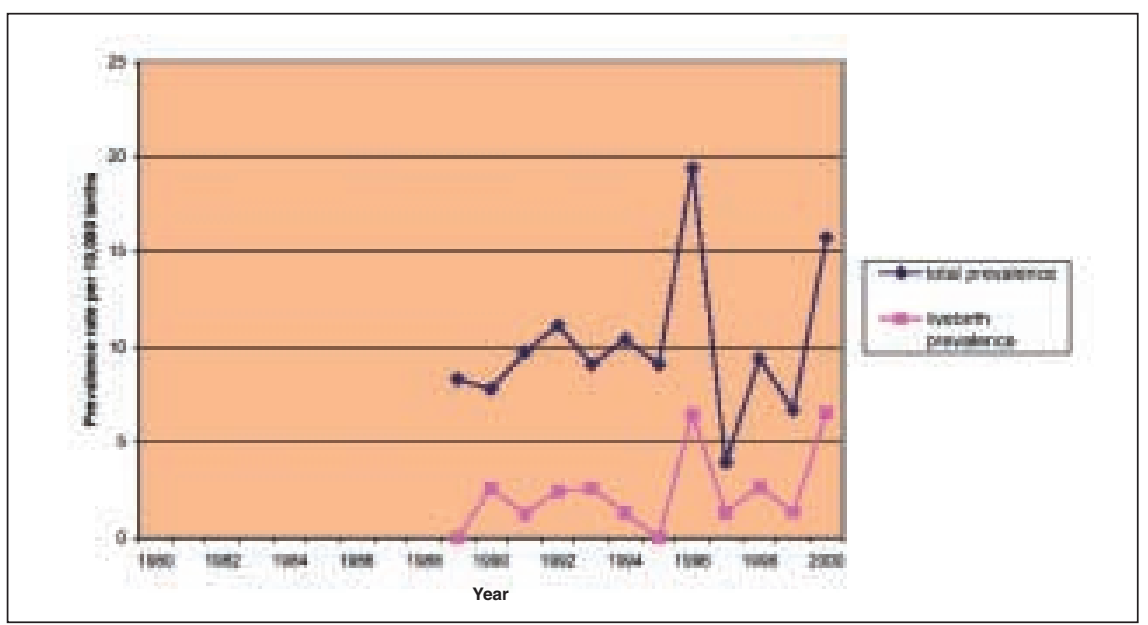

Figure 2

Switzerland (Vaud): Total Prevalence Rate for Spina Bifida.

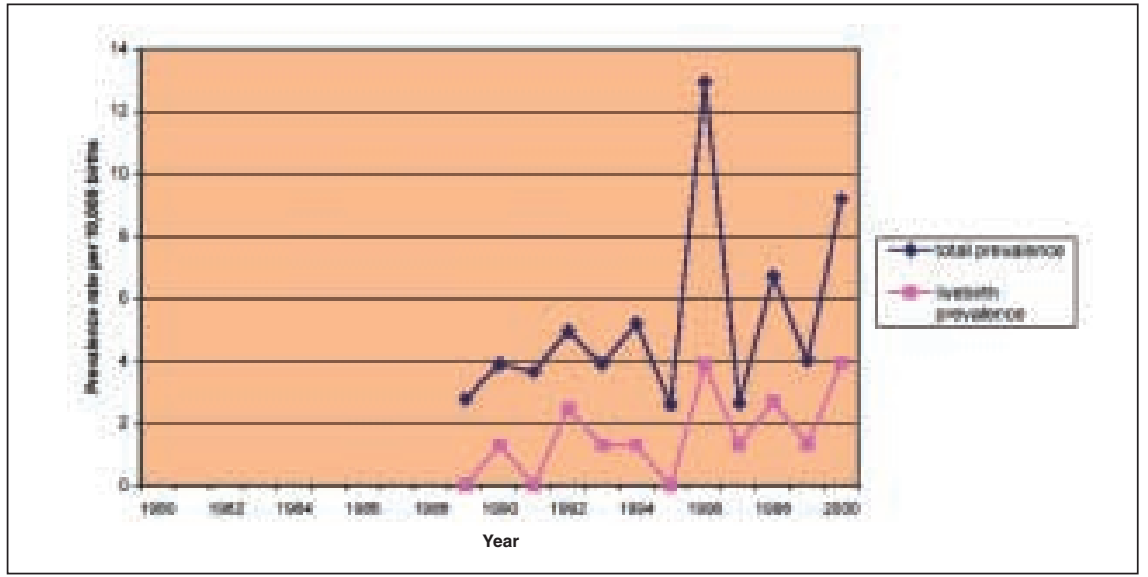

Figure 3

Switzerland (Vaud): Total Prevalence Rate for Anencephalus.

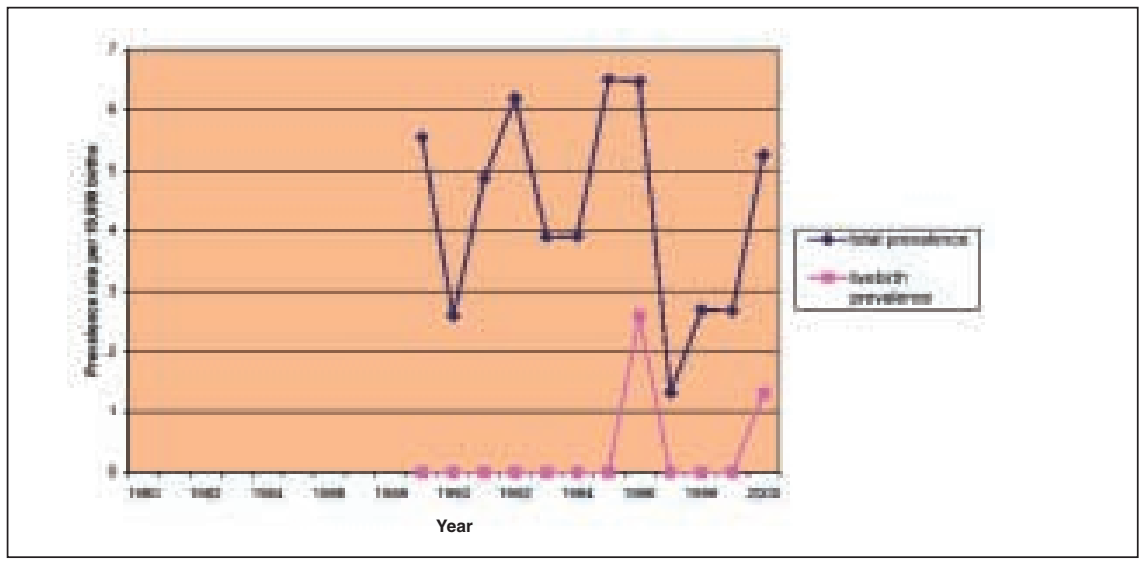

\section{References}

1 Tönz O, Lüthy J, Raunhardt O. Folsäure zur Verhütung von Neuralrohrdefekten. Schweiz Med Wochenschr 1996;126:177-87.

2 Tönz O, Lüthy J. Folsäure zur primären Verhütung von Neuralrohrdefekten Bulletin des Médecins Suisses 1996;77(14):569-72.

3 Eichholzer M, Lüthy J, Moser U, Stähelin HB, Gutzwiller F. Sicherheitsaspekte der Folsäure für die Gesamtbevölkerung. Praxis 2002;91:7-16.

4 Baerlocher K, Eichholzer M, Lüthy J, Moser U, Tönz O. Acide folique: Rapport d'experts de la commission fédérale d'alimentation sur la prophylaxie des anomalies du tube neural. Office fédéral de la santé publique, Berne 2002, $73 \mathrm{p}$. 